\title{
O CÍRCULO DE BAKHTIN E O MARXISMO SOVIÉTICO: UMA “ALIANÇA AMBIVALENTE”
}

Serguei Tchougounnikov

Universidade de Bourgogne - Dijon

\begin{abstract}
The aim of this article is to analyse different conceptions of language according to official marxist's point of view and compare them with the ideas of sovietics lectures of marxism, represented by Bakhtin's Circle (Valentin Volochinov, Mikhail Bakhtin, Pavel Medvedev) and Lev Vigotsky in the field of Psichology. Studies on language and Ideology are focused according their similarities and differences.
\end{abstract}

Key-words: Marxism, Sociology, Ideology, Language

Resumo: Este artigo tem como objetivo analisar diferentes concepções de linguagem segundo a perspectiva do "marxismo oficial" e compara-las com as idéias das leituras soviéticas sobre o marxismo, representadas pelo Círculo de Bakhtin (Valentim Volochinov, Mikhail Bakhtin, Pavel Medvedev) e por Lev Vigotsky no campo da Psicologia. Estudos sobre linguagem e ideologia são colocados em perspectiva segundo suas similaridades e diferenças.

Palavras-chave: Marxismo, Sociologia, Ideologia, Linguagem

\section{Os Componentes do Projeto "Sociológico" do Círculo}

As noções de "ideologema" e de "signo ideológico" são fundamentais no projeto "sociológico" do Círculo de Bakhtin.

O signo ideológico ${ }^{1}$ é definido como função de "refração" própria a todo fenômeno ideológico ou social. É um fenômeno de dupla face material, já que tudo é ideológico é necessariamente expresso em um material semiótico, e do ideário encarregado de um potencial avaliativo (ele é portador de avaliação social).

O signo ideológico encontra uma manifestação natural na entoação como expressão de valor ou atitude ideológica. Realiza o que Valentim Volochinov designa "a percepção de nós" (my-perejivanie) diferentemente da "percepção de moi” (jáperejivanie). Condiciona a percepção como "fato de consciência", isto é, como "fato social". Sem ele, a percepção, no sentido humano, a saber, inteiramente socializada, não seria possível. ( O Freudismo, Leningrado, 1927).

O signo ideológico é uma unidade constitutiva da consciência humana: com efeito, esta última é constituída por valores sociais, ideológicos ou coletivos. Ele corresponde a um veículo ou a uma percepção social, partilhada ou coletiva: nenhum veículo pessoal, "não-dialógico" ou ainda "monológico" torna-se possível por esta razão.

\footnotetext{
1 O conceito de "signo ideológico" é introduzido por Volochinov, aliás Bakhtin, na obra 'Marxismo e Filosofia da Linguagem'. Problemas fundamentais de um método sociológico aplicado à ciência da linguagem (1929).
} 
Pavel Medvedev introduziu os termos "ideologema" e "avaliação social".2 O ideologema é uma fusão do psicológico e do social. No campo da arte é a expressão, pelo viés das formas artísticas, do meio ideológico ou social do qual estas formas são oriundas. Ou ainda, é uma materialização dos valores e das funções ideológicas, nas formas artísticas, de um determinado meio social. Deste modo, o psíquico é social e, por conseqüência, ideológico.

Estas teses do Círculo de Bakhtin retomam e elaboram as teses marxistas clássicas, são elas que colocam o Círculo no rastro marxista. Todavia, sua compreensão de "ideologia" está longe de ser ortodoxa.

\section{Para a Genealogia da Noção de Ideologia}

Segundo Karl Marx, a ideologia é um reflexo invertido do real da sociedade na consciência dos homens. Suas representações, suas verdadeiras condições de existência obedecem ao mesmo processo de inversão que as imagens em um quarto escuro ou dos objetos sobre a retina. A consciência que os homens têm de suas próprias relações seria, portanto, ilusória e os sistemas elaborados neste quadro (religião, filosofia, moral) repousam, de acordo com Marx, sobre bases errôneas (A ideologia Alemã, 1846).

Nesta obra, Marx retém o sentido do termo ideologia, não como consciência, mas como sistema de opiniões que dominam o pensamento comum. Entretanto, este sentido do termo é relativamente tardio, aparece após o declínio da psicologia empirista e associacionista.

Inicialmente, a noção de ideologia elaborada por Destutt de Tracy e os "ideólogos" do final do séc. XVII é, antes de mais nada, a noção de uma "ciência das idéias" "3

Tratava-se do estudo das combinações das imagens, que, associando-se, formavam, crê-se, diferentes organizações conceituais. No início, a ideologia é considerada como consciência ou, ainda, ideologia e consciência não são distinguidas. ${ }^{4}$

\footnotetext{
${ }^{2} \mathrm{Em}$ 'O Método formal na História Literária. Introdução a uma poética sociológica (1928).

${ }^{3}$ Conforme Destutt de Tracy, Antoine Louis Claude. Elementos de ideologia, vol.4, Parte 1, Ideologia propriamente dita, Paris, 1801; Parte 2: Gramática, Paris, 1803; Parte 3: Lógica, Paris, 1805; Parte 4-5: Tratado da Vontade e seus efeitos, Paris, 1815. Destutt de Tracy, Antoine L. C. Princípios lógicos ou compilação de fatos relativos à inteligência humana. Paris, 1817.

${ }^{4}$ As ideologias representam uma geração posterior a dos grandes filósofos do início e da primeira metade do Século das Luzes, herdeiras diretas de Maupertius, de Condillac, de Turgot, etc... Antoine Louis Claude, Conde de Destutt de Tracy (1745-1836 filósofo, membro do Comitê de Insturção Pública, é visto como o chefe dos ideólogos. Foi eleito membro da Academia francesa em 1808. Em suas obras 'Elementos de ideologia', compostas por 'Ideologia', de 1801, 'Gramática Geral' (1803, última edição de 1817), 'Lógica' (1805) e 'Tratado sobre a Vontade' (1817), ele se coloca como porta-voz de um materialismo psicológico. A partir de uma teoria da sensibilidade, qu é, para ele, a origem das nossas idéias gerais e julgamentos, ele tira conclusões sobre a linguagem (a palavra, sobretudo) que teriam consideráveis influências. Trata de uma relação de conveniência/inconveniência que se coloca entre duas idéias. $O$ encontro entre a filosofia dos ideólogos com o início de um comparatismo histórico foi analisado por J.C. Chevalier In: 'Memorium Friedrich Diez (1976:175-195). A lingüística participa de um novo dispositivo que visa a definir as contribuições, as organizações sistemáticas, implicando uma história. Mas ela não tem sentido [...] a não ser através de um estudo sobre o nascimento das idéias, das formas linguiísticas, ligadas aos estados sociais engajados com uma finalidade que consiste na felicidade dos homens. Sem tomar posições sobre estas últimas conclusões, sem dúvida, interessantes - notamos o nascimento de um espírito novo, do qual participam o estudo das línguas e os fatos sociais, conforme Bertil Malmberg (1991: 242-43).
} 
Possivelmente, o "signo ideológico" recoloca no projeto do Círculo aquilo que a psicologia empirista do século XIX entendia por "elementos" psíquicos ou por " sensações simples", compreendidas como unidades mentais simples ( o vermelho, o azul, o doce, o amargo, etc...) que podem ser examinados como elementos. ${ }^{5}$ A sensação ou a percepção é um elemento da consciência ( por exemplo, na psicologia de Wilhelm Wundt). As percepções e as idéias somam-se às sensações. O termo percepção designa uma combinação de impressões empíricas externas, que constitui todo o objeto percebido, por exemplo, uma maçã. A idéia remete geralmente a combinações precedentes de provenientes da memória. ${ }^{6}$

Retornemos ao quadro estritamente marxista. Se as representações que compõem a ideologia são falsas com relação às realidades objetivas, elas representam um papel muito importante na vida social. É através delas que o grupo formula suas metas sociais, mas transvestindo-as de modo a dar-lhes um valor universal. Tal foi o percurso da nobreza feudal na idade média e, mais tarde, da burguesia.

Marx supunha que a ideologia desapareceria com a tomada de consciência clara sobre as relações sociais, reversão que, segundo ele, não poderia efetuar-se senão a partir da "práxis" revolucionária da classe mais desprovida, o proletariado.

Mas sobre a base do marxismo, o movimento operário criou uma nova ideologia que Lênin qualificou como "ideologia científica" [...]. Para Lênin, o problema se colocaria unicamente assim: ideologia burguesa ou ideologia socialista [...]. Não há um meio termo, já que a humanidade não teria elaborado uma terceira ideologia, e, portanto, em uma sociedade fraturada pelo antagonismo de classes, a ideologia não teria como existir fora ou acima das classes. ${ }^{7}$

O marxismo soviético do período stalinista (1920-1950) definiu a ideologia como "sistema de opiniões, de idéias e de conceitos que professam uma classe ou um partido político. As opiniões políticas, a filosofia, a arte, a religião são formas de ideologia. Toda ideologia é um reflexo da existência social, do sistema econômico que predomina em um dado momento. Em uma sociedade de classes, a ideologia é uma ideologia de classe. Ela exprime e defende os interesses de uma ou outra classe em luta. ${ }^{8}$

A ideologia é definida como motor da vida social, a luta das ideologias progressista e reacionária - reflete a luta de classes; em outras palavras, ela é o próprio motor da história. ${ }^{9}$

\footnotetext{
${ }^{5}$ Wayne Viney. Uma história da Psicologia. Idéias e contexto. Boston,London, 1993, p. 227-8.

${ }^{6}$ Ibid., p.228.

${ }^{7}$ Vladimir Lênin . Obras escolhidas, T.1, 1954, p.238.

${ }^{8}$ O Pequeno dicionário filosófico. Sob a direção de M. Rosenthal e P. Ioudine. Moscou, 1955.

${ }^{9}$ Encontramos na mesma fonte: “A ideologia desempenha um papel imenso na vida social, na história das sociedades. Refletindo as condições da vida material da sociedade e os interesses de uma ou outra classe, a ideologia, por sua vez, trata do desenvolvimento da sociedade. A ideologia progressista prende-se aos interesses das forças revolucionárias da sociedade. A ideologia da classe operária e o marxismo-leninismo [...] arma ideológica do partido comunista e da classe operária na transformação revolucionária, socialista, da sociedade. A força invencível desta ideologia provém do fato de que ela traduziu fielmente as leis objetivas do desenvolvimento histórico de nossa época. A ideologia burguesa contemporânea é, ao contrário, uma força reacionária. Ela se prende aos interesses da burguesia em sua luta contra a classe operária, contra o socialismo. Negação da ciência, idealismo (...) e obscurantismo, apelo ao chauvinismo e ao racismo (...), propaganda em favor do cosmopolitismo (...), tais são os aspectos da ideologia burguesa moderna. A vitória da classe operária e o triunfo do socialismo demolem a base que sustenta a ideologia burguesa. Tal influência não desaparece espontaneamente, mas somente no curso da luta renhida que a ideologia proletária não sustenta contra a ideologia burguesa.
} 
Ao qualificar a ideologia marxista de científica, o regime soviético deu um passo decisivo e criou, no seio da União Soviética, uma espécie de "ruptura epistemológica". A teoria das duas ciências - burguesia e proletariado - é oriunda dessa definição.

Conferindo, deste modo, um conteúdo positivo a uma determinada ideologia, os discípulos soviéticos de Marx romperam com a distinção entre ciência e ideologia. $\mathrm{O}$ termo ideologia passa, doravante, à ciência, a ciência torna-se necessariamente ideológica. Este termo é onipresente na URSS dos anos 20, o que aviva questão sobre a natureza e o valor da ideologia no Círculo de Bakhtin.

\section{Entre a "Filosofia Da Vida" e a "Psicologia Social"}

Lembremos que o essencial no percurso do Círculo de Bakhtin consistiu em produzir uma espécie de síntese entre o neo-kantismo e o marxismo. A terceira vertente do Círculo constitui-se da Filosofia da Vida e do idealismo da Escola de Karl Vossler.

Com relação às ciências humanas de seu tempo, o Círculo de Bakhtin está aquém. Ele propõe fundar um projeto sobre a filosofia alemã para a época, onde a filologia e a lingüística, influenciadas pelas idéias do estruturalismo nascente, não são mais, por excelência, as ciências alemãs.

Este embaraço particular para a ciência alemã tinha caracterizado a cultura russa do período dito "século do dinheiro" (fim do séc. XIX e início do séc. XX). Daí a dificuldade da leitura destes textos atualmente, onde as referências à "época alemã" das ciências da linguagem desapareceram completamente da paisagem das referências intelectuais.

O projeto do Círculo foi percebido a partir dos anos 1960 como concretamente original em função do esquecimento, pelas ciências da linguagem de hoje, do contexto e das referências filológicas do início do século.

Em particular, as referências à "Filosofia da Vida" (Lebenphilosophie) são fundamentais no projeto de lingüística sociológica de Volochinov. Trata-se de uma corrente ou de um modo de pensamento constituído na Alemanha e na França durante a segunda metade do século XX (Nietszche, Dilthey, Zimmel, Bérgson, Spebler, Klages, etc...).

Oposta ao racionalismo clássico e ao positivismo "mecanicista", esta corrente busca apreender a "vida" como um dado primeiro, como um processo orgânico integral que precede a divisão entre matéria e espírito, enquanto uma totalidade inacessível à razão e aos instrumentos conceituais das ciências positivas. ${ }^{10}$

A Filosofia da Vida assim como o neo-kantismo são hostis ao positivismo e situam a origem dos valores, não dentro de uma lei geral abstrata, mas na singularidade de um fenômeno individual. ${ }^{11}$

Quando Volochinov se debruça sobre questão genealógica da ideologia com vistas a estabelecer as leis de seu desenvolvimento na consciência humana, ele segue o percurso tradicional. Com efeito, todos os teóricos do marxismo propuseram-se a apresentar o mecanismo da gênese da ideologia - concebido como fenômeno da superestrutura -e a definir suas relações com a consciência (G. Plekhanov, V. Lênin, N. Bukharin).

Estes teóricos marxistas elaboram a noção de "psicologia social" reutilizada por Volchinov e que havia sido esboçada no estudo "O Dezoito Brumário" de Louis

\footnotetext{
${ }^{10}$ Sovremennaja zapadnaja filosofija [ Dictionaire de la philosophie occidentale moderne, Moscou, 1991]

${ }^{11}$ Tihanov, Galin. "Volochinov, Ideology and Language: the birth of marxist sociology, from the spirit of lebenphilosophie. In: Mikhail Bakhtin, London, Ed. Sage, 2002.
} 
Phillipe Bonaparte, onde Marx menciona "uma superestrutura dos sentimentos, ilusões, maneiras de pensar distintas e, singularmente, formadas que se adestram sobre as diversas formas da propriedade" e sobre as "condições sociais da existência". ${ }^{12}$ Em seu artigo de 1897 'A Concepção Materialista da História', Plekhanov recorre ao estudo do marxista italiano, Antonio Labriola, 'Ensaios Sobre a Concepção Marxista de História' (1896), no qual Labriola propõe-se a definir a função da "psicologia social." Esta última deve desempenhar o papel de mediadora na percepção da história como um todo orgânico.

A "psicologia social" é o lugar onde a experiência das condições sociais de existência humana se encontra transformada em diversas ideologias. ${ }^{13}$ Deste modo, de acordo com Galin Tihanov, a compreensão da ideologia, por marxistas russos e ocidentais, hesita entre dois pólos: ora é o produto secundário, um simples "reflexo" das infraestruturas; ora é um produto produtivo, uma força capaz, não somente de "refletir", mas também de "idealizar"

Em ‘As Questões Fundamentais do Marxismo’ (1908), Georgij Plekhanov busca o elo central entre um ponto de vista filosófico e a situação econômica do período concernente. Segundo ele, as diversas ideologias são mediatizadas pela mentalidade do povo ou pela "psicologia da época", mas não refletem diretamente a base econômica com sua ordem política. ${ }^{15}$

O projeto da "psicologia social", portanto, parece ligado aos princípios da "psicologia dos povos", enunciado por H. Steinhal e por M. Lazarus na revista Zeitschfrit für volkerpsychologie und sprachwissenchaft, a partir dos anos 1850, e também por W. Wundt (Völkerpsychologie, 1900-1920). Esta corrente é fundada em torno das idéias da psicologia universal que privilegia o papel dos processos "supraindividuais" ou "coletivos", heranças de Kant e de W. Humboldt. Fundada em torno da idéia da natureza coletiva da consciência, tal corrente transfere o psicologismo étnico ou ainda coletivo e social para os domínios da lingüística. ${ }^{16}$

Em sua obra de 1921 'O Materialismo Histórico', Nikolai Bukharin propõe-se a estabelecer uma relação "sociológica" entre a superestrutura e suas respectivas ideologias. Ele distingue duas entidades maiores no seio da superestrutura: a ideologia social e a "psicologia social". Para Bukharin, a diferença entre as duas reside no "grau de sistematização". Segundo ele, a "psicologia social" é uma solução a partir da qual a ideologia se cristaliza. A tarefa da ideologia consiste em sistematizar a "psicologia social."De outro ponto de vista, a ideologia é rígida e estática, ela é, desta perspectiva, dependente da "psicologia social", que é mais móvel e sensível às mudanças. ${ }^{17}$

Galin Tihanov vê na instabilidade das relações entre a ideologia e a "psicologia social" o mesmo mecanismo que se encontra na "Filosofia da vida" de Georg Simmel (1858-1918), onde as forças de desenvolvimento orgânico estão em conflito com as forças de solidificação e de consolidação. ${ }^{18}$

\footnotetext{
${ }^{12}$ Ibid., p.337.

${ }^{13}$ Ibid., p.325.

${ }^{14}$ Ibid., p325.

${ }^{15}$ Ibid., p.324. Ver a noção de "psicologia social em Plekhanov: 'Ensaio sobre o desenvolvimento da concepção monista de história' (1895); 'Obras filosóficas', t1, t2,t3 (1981); 'Contribuição à psicologia do movimento operário.' In: Gorki, Maxim ‘Os inimigos (1907) ‘As questões fundamentais do marxismo' (1908); ‘A ideolgia do pequeno burguês de nosso tempo' (1908) In: 'Obras filosóficas', t5, 1983.

${ }^{16}$ Conforme Wundt, Wilhelm. Völkerpsychologie. 1900.

17 Tihanov, Galin op.cit.

${ }^{18}$ Ibid.,p.326.
} 
Neste contexto, com efeito, Volochinov refere-se à Simmel. Em seu próprio projeto, Volochinov não fala da "psicologia social", mas da psicologia do cotidiano (zjiznennaja ideologija), literalmente, a psicologia de todos os dias, a psicologia da vida. Seu projeto coloca unidade fundamental entre a ideologia e a "psicologia social", redefinida como psicologia do cotidiano. Portanto, o termo zjiznennaja $(z j i z n=$ vida) permite perceber a influência da "Filosofia da vida" de Simmel na concepção de Volochinov.

A filosofia e a sociologia de Georg Simmel, Professor das Universidades de Berlim (1901-1914) e de Estrasburgo (após 1914) estão inscritas na tradição morfológica alemã. Suas obras essenciais foram traduzidas e publicadas na Rússia entre 1908 e $1928 .^{19}$ Os conflitos vividos pelo indivíduo encontram fundamento profundo no mecanismo da vida. A "vida" se realiza pelas limitações que ela dá a si própria ao criar as formas. A forma é o limite superior, é a morte; a morte não vem do exterior, está intrincada na própria vida. São formações relativamente estáveis. Criadas pela "vida", elas se opõem à sua natureza mutante. Mehr-Leben e Mer-als-Leben são formas da cultura. A "Filosofia da vida" transforma-se, na obra de Simmel, em Filosofia da cultura. A "vida" da cultura passa pelo engendramento de novas formas culturais.

Ao envelhecer, estas formas petrificadas tornam-se um freio para o desenvolvimento da vida. Eliminadas, são substituídas por novas formas condenadas a viver o mesmo destino. A tragédia da cultura reside na fatalidade destes conflitos do devir. O trato dominante da cultura moderna é, segundo Simmel, a luta da vida contra o princípio da forma.

Na qualidade de sociólogo, Simmel elabora uma concepção fundada sobre a interação do "conteúdo" (metas historicamente determinadas, motivos de interação humana) e "formas", isto é, a maneira universal de encarnar e realizar os conteúdos historicamente mutáveis. Esta interação de duas instâncias, a forma mais o conteúdo que a repõe, conduz à realização da sociedade. A Tarefa da "sociologia pura" consiste em estudar e classificar as formas; a tarefa da sociologia filosófica é de acompanhar os destinos históricos destas formas com relação a seu conteúdo culturalmente determinado. ${ }^{20}$ Trata-se de uma ciência das formas orgânicas, de uma disciplina morfológica. A concepção de Simmel insere-se na tradição morfológica alemã, fundada por Herder e Goethe e desenvolvida por Spengler ( 'O Declínio do Ocidente', 1922).

Para Spengler $^{21}$, o meio de conhecimento das formas mortas é a lei matemática. O meio de compreensão das formas vivas se dá pela analogia. Assim se distinguem a polaridade e a periodicidade do mundo. A "forma interna" está presente na morfologia de Spengler como "sentimento de uma fronteira precisa.". Esse sentimento reocupa-se de uma "forma interna" determinada pelas propriedades da espécie na ual se aparta um fenômeno analisado. ${ }^{22}$ A forma própria dita também "real" de um sistema autônomo

\footnotetext{
19 'Problemas da filosofia da história' (1898); ‘A religião' (1909); ‘A diferenciação social' (1909); 'O Conflito da cultura moderna' (1928).

${ }^{20}$ Sovremennaja zapadnaja filosofija. [Dicionário da Filosofia Ocidental Moderna] op.cit., p.108109.O essencial da filosofia e da sociologia de G. Simmel está exposto nas seguintes obras: 'Sociologia e epistemologia.' Paris, Presses Universitaires de France, 1981. 'Simmel e as normas sociais.' (Atas do Colóquio: Simmel, Pensador das Normas Sociais). Paris, Ed. L'Harmattan,1996. 'Sociologia, Estudo sobre as formas de socialização. Paris, Presses Universitaires de France, 1999. 'A filosofia da aventura. Ensaios. Paris, Ed. L'Arche, 2002. 'A forma da história e outros ensaios.' Paris, Ed. Gallimard, 2004.'Kant e Goethe. Contribuições à história do pensamento moderno. Paris, Ed. Gallimard, 2005. 'Para compreender Nietzche. Paris, Ed. Gallimard, 2006. 'O problema da sociologia e outros textos. Paris, Ed. du Sandre, 2006.

${ }^{21}$ Spengler, O. O declínio do ocidente.

${ }^{22}$ Ibid., p. 150 .
} 
fechado inclui as etapas de crescimento desse sistema, suas idades sucessivas. ${ }^{23} \mathrm{~A}$ "lógica orgânica" da história é sua "estrutura periódica", é seu destino e não sua causalidade.

Para Spengler, como para Goethe, a Gestalt opõe-se à lei, e a "natureza viva" à "natureza morta"; o mundo como organismo, ao mundo como mecanismo. ${ }^{24}$

A civilização como "destino da cultura" exprime uma estrita necessidade orgânica. É o ápice da "morfologia histórica", o estado mais artificial, o estado limite do sistema da cultura. ${ }^{25}$ Há uma etapa de acabamento quando o que se transforma recoloca o processo da transformação? É a morte que segue a vida. A civilização "pura" como processo histórico consiste em concluir uma "desmontagem" ou uma "desconstrução" (Abbau) das formas tornadas inorgânicas e mortas. ${ }^{26}$ Para spengler, as culturas são os organismos e a história universal, sua "biografia geral". A morfologia comparada mostra as manifestações repetidas da forma interna dos fenômenos, gestalts puras.

A "vida" da linguagem, para Volochinov, situa-se no devir. Ela se completa no "meio ideológico", espaço onde aparecem as formas linguageiras orgânicas.

Volochinov define a ideologia do cotidiano como o conjunto da experiência da vida e das expressões externas ligadas a esta experiência. São os "elementos" da palavra interna e externa que dão sentido a cada estado de consciência. Enfim, Volochinov diz que o termo corresponde essencialmente ao que a literatura marxista designa como a "psicologia social". O ato (postupok) aparece como unidade da ideologia do cotidiano. ${ }^{27}$

De acordo com Bukharin, uma mudança na "psicologia social" conduz a uma mudança correspondente na "ideologia social". Em geral, as relações entre ambas permanecem ambíguas. É a ambigüidade das relações entre infraestrutura e superestrutura, que não parecem mais partilhar a simples relação de determinação direta ou de simples "reflexo".

Volochinov acentua a vantagem de interação entre a "psicologia social" e a "ideologia social"., a saber, entre a infra e a superestrutura. Esta última (a superestrutura) aparece como capaz de agir sobre a primeira. Com efeito, os modos ideológicos de expressão (ciência, arte, religião) exercem uma forte influência sobre a experiência ou a "percepção" (perezjivanije). ${ }^{28}$ A teoria geral das ideologias, revista por Althusser, parece emergir. ${ }^{29}$ É a "ideologia do cotidiano" (equivalente à "psicologia social") que, na obra de Volochinov, aparece como uma fonte das "significações ideológicas". Por sua vez, estas se encontram transformadas em produtos da ideologia no sentido estrito.

A linguagem é colocada, por Volochinov, como um elemento da superestrutura, ele compartilha com o ponto de vista de Marr com relação a este aspecto (esta posição é sobretudo clara no artigo de Volochinov "O que é a linguagem", 1929). Volochinov faz derivar a linguagem da interação social. Ela nasce no espaço interdiscursivo, seu elemento natural. Este espaço corresponde à exterioridade da consciência social. Em suas formas sociais de realização (dialógicas, interativas), a linguagem é a "ideologia cotidiana" ou, para a "psicologia social", efetiva.

\footnotetext{
${ }^{23}$ Ibid., p. 151 .

${ }^{24}$ Ibid., p. 156.

${ }^{25}$ Ibid., p. 163 .

${ }^{26}$ Ibid., p.164.

${ }^{27}$ Referenciado em Galin Tihanov, op.cit.,p.327.

${ }^{28}$ Ibid., p.327.

${ }^{29}$ Ela será, mais tarde, questão sobre a diferença importante entre os percursos de Althusser e Volochinov.
} 
É de tal espécie, do interior do indivíduo, enquanto "consciência social coletiva" (de classe) que a linguagem forma a consciência individual. As "formas da palavra" se acham engendradas nesta interação verbal externa. Esse processo de geração desemboca, finalmente, na mudança das formas da linguagem. Tais formas modificadas retornam, a seguir, à consciência individual, impregnada pelas transformações. ${ }^{30}$

De acordo com Galin Tihanov, os avanços de Volochinov conduzem à conclusão de que a linguagem, para este, não é uma superestrutura na realidade. A razão é que ela participa das ideologias sem fazer parte destas.

É neste sentido que ela é "neutra", sob a ótica de toda função ideológica (conforme sublinha Volochinov). A palavra (slovo) não faz senão o acompanhamento "como um elemento necessário" de toda "criação ideológica".

Para Galin Tihanov, a linguagem, em Volochinov, não pertence à superestrutura, pois sua função consiste, preferencialmente, em assegurar a mediação, manter reunidas diversas partes heterogêneas da última. ${ }^{31}$ Pode-se pensar, a partir desta definição, que a palavra (a linguagem) não é, portanto, senão o suporte de toda "atividade ideológica" e que ela é, por sua vez, neutra. Entretanto, esse suporte está longe de ser passivo: trata-se de um suporte ativo, através do qual toda "atividade ideológica" é, não somente acompanhada mas também comentada ou avaliada "socialmente".

A "ideologia cotidiana" (ou como Volochinov designa "ideologia da vida") constitui o meio natural onde se desenvolvem e se completam os "fatos ideológicos" e os "ideologemas". Extraídos do meio, todos os fenômenos ideológicos são mortos, eles se tornam "monumentos" das ideologias passadas.

A ideologia dominante externa, sustentada pelas formas lingüísticas e pela "palavra externa" compõe uma "consciência oficial". Esta última pode, eventualmente, entrar em conflito com a "consciência não-oficial", isto é, com a palavra interna do indivíduo.

\section{O Modelo de Volochinov- Humboldt: "energeia" versus "ergons"}

O modelo dinâmico de Volochinov coloca a questão crucial dos "produtos ideológicos", própria a uma ou outra "ideologia oficial". No seio de tal modelo, a objetivação dos "produtos ideológicos" é uma exigência absoluta. As significações ideológicas buscam a materialização, buscam dotar-se de um material semiótico, revestir-se deste material. Tais produtos acabados da "criação ideológica", ditos "ideologemas", constituem a materialidade da "ideologia cotidiana". Contudo, o acabamento dos "produtos ideológicos", sua inscrição em formas ideológicas precisas, significam sua morte. O mecanismo de sua formação é o da "negatividade". W.V. Humboldt fala a este respeito, dos "ergons", dos produtos acabados ou mortos, fora do devir da linguagem, como "energéia". 32 De acordo com Humboldt, a "energéia", o dinamismo da linguagem, reside em sua forma interna.

A "forma interna" é uma maneira particular de ligação, para cada língua, entre o som e o sentido. Ela registra os tratos particulares do espírito (geist) de uma nação, encarna seu "gênio." A forma interna veicula, por consequiência, a "visão de mundo" (Weltanschaung) própria de uma língua nacional. Ou ainda, é o recorte da forma interna que cria a "visão de mundo."

\footnotetext{
${ }^{30}$ Volochinov, V. “Čto takoje jazik?” (“O que é a linguagem?”) In: Literaturnaja uceba, 1930.

${ }^{31}$ Galin Tihanov, op.cit., p.327-29

${ }^{32}$ Humboldt, W.V. Schriften zur sprache, 1995.
} 
Para Humboldt ${ }^{33}$, o conceito tem uma forma fônica que busca tornar objetivo o pensamento na linguagem. É a forma interna, expressão do espírito que constitui o modo de ligação das categorias do pensamento com as formas da matéria lingüística. A "forma interna" é uma mediação entre os "tecidos" do pensamento e da linguagem. É ela que faz da linguagem um sistema modelisante. ${ }^{34}$ Este breve apanhado mostra as numerosas homologias entre o conceito de "forma interna" de Humboldt e o conceito de "palavra interna" de Volochinov.

A idéia central de Humboldt postula o crescimento autônomo e ilimitado da linguagem. Cada ato de linguagem modela sua origem: cada emprego lingüístico é o renascimento da totalidade da linguagem. Todo locutor recria a linguagem integralmente no momento em que fala, mas ao faze-lo ele refaz o trabalho das gerações que o precederam.

Tanto para o indivíduo como para a coletividade lingüística, a linguagem é um espelho onde eles se refletem. É uma exteriorização do espírito do povo, onde o espírito do povo é refletido por sua linguagem. ${ }^{35}$ A linguagem é o "órgão do pensamento" no sentido de que a união dos dois - da linguagem e do pensamento - é orgânica, ela cria o organismo. Entretanto, o indivíduo e a coletividade falante são, por sua vez, criados pela linguagem.

A linguagem, segundo Humboldt, é marcada pelo selo da matéria. Vemos desenvolver-se a luta hegeliana entre o espírito e a matéria. O pensamento, instância imaterial, luta contra a linguagem para se emancipar de sua materialidade. As palavras, estas "vestimentas" do pensamento são muito limitadas para ele. No curso desta luta, o espírito transmite à palavra aquilo que ele apreende; alimentada pelos frutos da progressão do espírito, a palavra sofre uma metamorfose ascendente, ela se expande e se enriquece. ${ }^{36}$ A palavra se encontra arrebatada no itinerário do espírito (steingerung, para retomar, nos termos de Goethe, o processo de intensificação).

O pensamento adquire clareza no som articulado; a representação clara guiada pelo som articulado constrói um conceito. Tal é a proto-forma primitiva; a palavra percorre o caminho do estado do som difuso ao conceito elaborado. A planta de Goethe acompanha a mesma metamorfose a partir de uma folha primitiva, grosseira, até a pétala elaborada e refinada pelo trabalho dos sumos internos. A linguagem, sendo um ato, um movimento, um devir, apresenta resultados concretos desse ato como pontos de chegada dos produtos mortos integrados nesse movimento ou nesse devir. A cada nova etapa há uma diferença entre os produtos linguageiros. Cada novo ciclo reproduzido, da vida da linguagem, retoma os produtos e os modifica. Sendo o desenvolvimento da linguagem permanente, seus produtos vivem uma metamorfose contínua. Reconhece-se, aqui, o mecanismo da morfogênese formulado pelo texto de Volochinov. A "criatividade ideológica" externa e seu efeito formador sobre a consciência individual modela esse desenvolvimento.

\section{Volochinov e Hegel: linguagem como "Instrumento de Mediação"}

Hegel (1770-1831), cujo pensamento constitui a verdadeira raiz da dialética de negatividade, fala da carga negativa, a de "alienação", própria dos objetos e da técnica em geral. $\mathrm{O}$ homem produz os utensílios, pois ele deve transfigurar a matéria inerte. Uma vez o conceito e o logos encarnados, o homem nega a natureza e suprime a

\footnotetext{
${ }^{33}$ Ibid., p.44-59.

${ }^{34}$ Ibid., p. 82-91.

${ }^{35}$ Ibid., p. 34-38.

${ }^{36}$ Ibid., p. $59-81$
} 
matéria. É ele o ser negativo na medida em que suprime o ser. O trabalho humano é uma atividade formadora dirigida contra a matéria morta. "O instrumento é, essencialmente, o ato de possibilitar a morte." ${ }^{37}$ Ele é esta mediação, através da qual se efetua a síntese do objeto e do sujeito. Mas o instrumento, o objeto fabricado, é o espelho fiel do espírito. Uma vez a exteriorização realizada pela técnica, é necessário compreender os objetos fabricados. Os instrumentos, no seu conjunto, refletem o espírito, são etapas materializadas do seu devir. Ou dito de outro modo, a linguagem é, para Hegel, um instrumento, reconstrói a negatividade do ser humano. Ela é o primeiro ato da vontade de potência. É através da linguagem que o homem realiza seu domínio sobre a natureza, sobre o mundo dos objetos.

Dar um nome a um objeto significa aniquilá-lo e fazer qualquer coisa de ideal. É por esta idealização que a consciência se apropria das coisas. Como trabalho, a linguagem participa desse excesso de alteridade, da forma estrangeira que é, segundo Hegel, a própria condição humana. A escala se reencontra como um ser independente na forma que ele confere ao objeto. O homem falante, o locutor adquire sua essência e sua liberdade nos produtos de sua palavra e de suas atividades discursivas.

O instrumento ou a máquina é o prolongamento da ação coletiva de (moi). É uma unidade autonomizada, capaz de auto-atividade. É também "a pura tradução da essência de si mesmo." $" 38$

No instrumento, a negatividade adquire uma existência objetiva, autônoma. A linguagem, a palavra retoma este trabalho de "negatividade infinita." É na linguagem que a essência humana se reflete e se libera de suas determinações naturais, a saber, a natureza. É pela linguagem, na condição de trabalho, atividade produtiva, que se encontra a "alienação" essencial do homem. ${ }^{39}$

A linguagem é concebida por Hegel como uma forma de violência: o conceito destrói o objeto que nomeia. A apropriação do mundo passa por seu massacre com o auxílio da linguagem. É uma espécie de canibalismo, onde o universo dos objetos se encontra devorado pelas palavras.

Mas Humboldt, para o qual a dialética de Hegel é o ponto de partida, modela de outro modo a progressão da linguagem. Segundo ele, a relação particular do homem com o mundo, por intermédio da linguagem, é da ordem da afinidade ou da simpatia. ${ }^{40}$

${ }^{37}$ Conforme Papaioannou Kostas. Hegel, 1962.

${ }^{38}$ Ibid., p.73.

39 A alienação é o conceito fundamental do hegelianismo. Para Hegel, existe identidade e contradição entre o sujeito e o objeto, entre o pensamento e o real. Esta unidade contraditória do ser é possível porque o real (a natureza, após a história humana) é o "outro" do sujeito (a idéia absoluta) sua alienação. A idéia se aliena na natureza. Após, através dos conflitos da história humana, realiza-se uma dialética da desalienação.

${ }^{40}$ Se para Humboldt, tradicionalmente, a linguagem é um produto espontâneo, arbitrário do entendimento, como signo material ligado a conceitos gerais, o torneio propriamente humboldtiano, de acordo com Trabant, consiste em postular a linguagem como elemento intermediário ativo entre o homem e o mundo e formador. Em uma carta de Humboldt a Schiller, em 1800, a linguagem é apresentada como um mediador que opera entre o entendimento e a receptividade como "espelho do mundo" e "órgão do homem" ao mesmo tempo. A linguagem cria a possibilidade de uma união mais íntima com o mundo, que é produzido com e pelos sons. A linguagem é posta como um conjunto sistemático apresentado em termos de organismo e de um produto do trabalho do espírito. Este torna-se a síntese do mesmo modo que a análise constitui a essência da criação lingüística do pensamento. (J. Trabant Humboldt ou le sens du langage, op. Cit., p.26-7). O motivo formalista do papel ativo formador da substância de expressão encontra-se também pré-figurado na lingüística de Humboldt. Segundo Humboldt, “ a linguagem é senão absolutamente o meio físico, o meio através do qual o homem se forma a si próprio e forma ao mesmo tempo o mundo, ou pelo qual ele se torna consciente de si próprio ao separar o mundo de si ." (citado por J. Trabant,. Ibid., p.25). 
É por tal razão que a linguagem não destrói mais o mundo dos objetos. Ela encaixa o espaço do mundo externo e da consciência.

Ao postular o desenvolvimento do discurso, Volochinov alia-se à visão de Humboldt.

Abolimos, deste modo, a noção de trabalho como código de leitura e como unidade de análise. É nesse ponto que a análise marxista reúne as construções da dialética negativa.

\section{Volochinov/ Vygodskij: A "Lingüística Sociológica e a Psicologia Materialista"}

A "psicologia materialista" de L. Vygotsky, da qual se extrai a "lingüística materialista" de Volochinov, parece possuir um fundamento marxista sólido. Para Vigotsky, assim como para Volochinov, a linguagem é antes de tudo processo discursivo, processo de produção. ${ }^{41}$

Parece possível restituir o mecanismo de transformação da consciência lingüística pelo linguagem, a partir do modo como esta é concebida pela psicologia materialista de Vigotsky e pela lingüística sociológica de Volochinov. ${ }^{42}$

A aquisição assim como a utilização da linguagem é um processo produtivo: implica a objetivação de representações.

Esse processo se conclui nos produtos discursivos exteriorizados (enunciados). Estando exteriorizados, tais produtos discursivos adquirem novas formas de existência. Tornam-se objetos ideológicos, objetivados e perceptíveis. Sob a forma exteriorizada, o produto discursivo, que refrata a realidade, torna-se novamente um objeto de refração para o locutor. Este estabelece, necessariamente, uma relação entre o enunciado e suas próprias pressuposições de partida. Daí deriva um redobramento, uma clivagem entre as noções de partida e chegada. Esta ruptura exerce seus efeitos sobre a consciência do locutor.

A transformação da consciência do sujeito falante completa-se no intervalo entre a não-materialidade da "palavra interna" de partida e a materialidade da palavra externa. A mudança ocupa o lugar de um efeito de feed-back entre as representações de partida e de chegada. A linguagem como "consciência prática" extrai o conteúdo psíquico das idéias, dos objetos e de suas relações.

No modelo de Hegel e de Humboldt, o pensamento, a consciência são engendrados pela linguagem. Na ótica da "psicologia materialista" é a consciência como conteúdo que está na origem da linguagem e de suas formas.

A linguagem é uma forma de existência da consciência. As palavras não são substitutas dos objetos; as palavras e os conceitos são cristalizações dos esforços produtivos ou do trabalho, estando associados aos objetos nomeados.

As palavras são condensados de atividades produtivas e de práticas sociais associadas aos objetos designados. A consciência é o produto da atividade humana no mundo dos objetos. É nesta atividade necessariamente dialógica e social que o homem se apropria de sua consciência, sua essência humana. A consciência é o produto destas

\footnotetext{
${ }^{41}$ Ver a respeito deste tema: Emerson “A palavra externa e a fala interior. Vigotsky e a internalização da linguagem. In: Mikhail Bakhtin. London, Sage, 2002, p.341-359.

${ }^{42} \mathrm{Na}$ falta de desenvolvimento explícito do tema, recorremos ao texto de Aleksadr Leontiev (19031979), discípulo e continuador de Vigotsky na área da psicologia. "O Marxismo e a psicologia. Sobre os fundamentos gerais da psicologia marxista. In: Leontiev, A. Dejatel nost soznanik. Lithnost, Moscou Académia,2004.
} 
relações sociais particulares que os homens mantêm no curso do processo de produção. $^{43}$

A psicologia materialista assume e retém as idéias de Humboldt, a partir das quais a linguagem, por sua origem, está indissociavelmente ligada à consciência. A linguagem fornece à consciência o substrato material necessário. A consciência encontra na linguagem sua encarnação perfeita. Ela não existe de modo objetivo, fora da linguagem. Pode-se falar da dominância humboldtiana que reúne a psicologia materialista (Vigotsky) e a lingüística sociológica (Volochinov) ao "marxismo oficial" em sua reflexão sobre a linguagem.

Por que o "marxismo oficial" rejeitou, entretanto, tais concepções que parecem convir à filosofia marxista? É também mais surpreendente que o marxismo soviético tenha, finalmente, retido numerosos postulados destas teorizações heréticas. Trata-se, em particular, da afirmação de continuidade entre o pensamento e a linguagem ( $o$ marxismo oficial canonizou a idéia de Marx, segundo a qual a linguagem é a consciência prática real). Sobre o reflexo da evolução do pensamento pela linguagem, Lênin, em seus Cadernos filosóficos, cita esta idéia de Hegel com aprovação,( não obstante a presença de um ponto de interrogação). Enfim, a afirmação da continuidade ideológica entre a consciência e a linguagem (expressa de modo definitivo por Stalin em sua intervenção sobre o lingüístico), o substrato material e social na origem da linguagem e da consciência; a idéia de que a consciência é um produto da interação e da atividade produtiva; a impossibilidade de separar linguagem e pensamento.

O marxismo oficial define a psicologia desde uma perspectiva cognitiva. Sua função essencial, com efeito, consiste em refletir o mundo externo. Como recurso último, a psicologia científica busca refletir sobre o movimento dialético na matéria. A psicologia é social e científica na medida em que é capaz de descobrir e registrar este movimento dialético objetivo. Daí o paralelismo entre o mundo, tal como é, pelo modo como é governado por leis dialéticas intrínsecas, e o psiquismo social, objeto da psicologia científica.

O desenvolvimento psicológico é um processo natural na medida em que o meio social é o meio natural do homem. Assim, tanto em Volochinov como no marxismo oficial, a consciência com seu suporte lingüístico é percebida como propriedade da matéria altamente organizada. A organização na matéria condiciona o aparecimento da consciência. Esta é, de fato, metamorfose da matéria. Sua origem se encontra na escrita sobre a metamorfose compreendida no sentido de Goethe (a idéia da planta e do animal primitivo). ${ }^{44}$ É um produto do trabalho interno do substrato material. Este coroamento da metamorfose do suporte material é uma exposição exterior do trabalho interno da evolução. A consciência, zona de convergência de tendências a obras presentes na matéria, é nutrida pela simetria e pela organização.

Esta dupla visão é convergente. O marxismo oficial, entretanto, recusa o radicalismo de Vigotsky e Volochinov, no que concerne à definição de linguagem, e, por conseqüência, em termos de superestrutura.

O marxismo oficial confina a superestrutura ao papel de um reflexo passivo da infraestrutura. Ele elimina, de modo definitivo, a questão do efeito inverso da superestrutura sobre a consciência produzida. Passa a definir a consciência como conteúdo puro, a forma desse contínuo é declarada inexistente. Ela não é senão uma simples continuidade mecânica, uma simples expressão externa do contínuo em questão. Privada de importância e de autonomia, a forma é inteiramente dependente da continuidade da consciência. A linguagem sendo colocada como forma de organização

\footnotetext{
${ }^{43}$ Ibid., p.21-7.

${ }^{44}$ Goethe J. (1790) La metamorphose des plantes. Paris, 1975.
} 
verbal da consciência, aparece, por conseqüência, como destituída de importância para esta última. A forma é bem excluída do funcionamento da consciência, ela perde seu estatuto morfogênico.

Em relação a Vigotsky e Volochinov, suas posições aproximam-se das posições do formalismo russo. Para o formalismo, a forma nova cria um conteúdo novo. Pode-se, doravante, postular o efeito da forma sobre o contínuo e a ruptura produtiva entre ambos. O motor do desenvolvimento é colocado para fora do objeto que evolui.

A ótica oficial do marxismo é inversa. O conteúdo da consciência aparece como o dado intrínseco, como simples efeito do meio ideológico homogêneo. A forma não faz senão refletir os estágios de desenvolvimento deste motor intrínseco. O conteúdo emana da forma que é sua expressão orgânica.

O marxismo oficial elimina a clivagem entre a forma e contínuo. A evolução descontínua e mutacionista, procedendo por saltos, é substituída pela evolução contínua gradual. É o dispositivo negativo que se torna excluído do mecanismo de desenvolvimento. Eliminando a negatividade, o marxismo oficial elimina a noção de "ideologia" como falsa consciência, como "negatividade", ou a ruptura entre as dimensões interna e externa.

O marxismo oficial produz a "ideologia positiva": esta última é científica ou objetiva, na medida em que ela reata a ordem do mundo, as leis e a estrutura da matéria. Não é mais uma ideologia no sentido do marxismo clássico (portanto, uma deformação da consciência, um grau preciso de alienação). É simplesmente, a imagem ou reflexo fiel do mundo, tal qual ele é. Esta ideologia positiva implica a compreensão absoluta do mundo e a resolução do enigma da matéria. A estrutura da consciência ideológica deste tipo é, com efeito, idêntica à estrutura desta última.

Seguindo Hegel e Humboldt, o marxismo soviético observa que a linguagem e o pensamento evoluem paralelamente. A linguagem é definida como intimamente ligada à natureza humana e como manifestação orgânica desta natureza.

Do ponto de vista marxista, trata-se da essência produtiva e social do homem. Para Hegel, o trabalhador descobre que o mundo das coisas não é, de modo algum, uma substância diferente da consciência. ${ }^{45}$

De acordo com a ótica marxista, o trabalhador descobre sua consciência como uma força material e esta descoberta passa pelo viés da linguagem. No modelo de Hegel e Humboldt, a essência do pensamento se encontra alienada na matéria lingüística. As formas linguageiras acabadas são os produtos alienados do espírito ou do pensamento.

No modelo do marxismo soviético, contudo, a consciência não está mais alienada na linguagem, nem em seus produtos. Ela ultrapassa sua alienação em relação à linguagem: em termos hegelianos, esta consciência torna-se "uma consciência de si." É o triunfo do espírito que ultrapassa sua negação, que transpõe a matéria lingüística, enquanto negação.

Esta consciência que resolve a matéria que é, ela própria tornada matéria, rejeita logicamente a idéia formalista ou construtivista sobre a consciência, a idéia do psiquismo humano em construção. O marxismo oficial estagna a circulação dos signos ideológicos entre o meio e a consciência. Não é mais questão de um retorno diferenciado na consciência. $\mathrm{O}$ meio social e a consciência formam uma continuidade, um meio perfeitamente homogêneo.

\section{O Pensamento de Volochinov em Face da Análise do Discurso}

\footnotetext{
${ }^{45}$ Papaioannoukostas. Hegel. Paris, Seghers, 1962, p.74.
} 
É neste ponto que reside a diferença entre a posição do marxismo oficial e a posição de Volochinov. Para ele, tudo se dá pelo desenvolvimento ideológico da consciência, assegurada pelo retorno permanente dos signos ideológicos e por seus impactos. A origem desse desenvolvimento se encontra em Volochinov (assim como nos formalistas) no descolamento entre os dois estados sucessivos da consciência.

Mas a autonomia da superestrutura e, por conseqüência, da ideologia posta por Volochinov está compromissada com a continuidade entre a "psicologia social" e a ideologia formulada de acordo com sua concepção. Para Volochinov, deste modo, parece impensável dissociar o autor de um enunciado em sujeito falante, em locutor e enunciador, como fez Ducrot em sua teoria polifônica da enunciação. ${ }^{46}$ Esta distinção, entretanto, foi elaborada a partir das idéias de Bakhtin sobre a polifonia e sobre a pluralidade de vozes na enunciação.

Para Volochinov, entretanto, o acontecimento discursivo reside na fusão destas instâncias, resultante da continuidade orgânica entre a psicologia social e a "ideologia'. Para Ducrot, o enunciador está para o locutor, assim como a personagem está para o autor; por sua vez, o locutor equivale ao narrador e é neste sentido que ele opõe o sujeito falante ao sujeito empírico.

Para Volochinov o "tema", enquanto terceira personagem discursiva, adquire a materialidade de um herói autônomo. É como tema, isto é, como um personagem autônomo do discurso que o sentido adquire lugar. Mas essas três instâncias - sujeito falante, locutor e enunciador - são pensadas por Volochinov na unidade do enunciado plurivocal. São diversos estágios da metamorfose global do enunciado.

Não podemos extraí-los, pois sua realidade discursiva, sua eficácia depende da fusão destas três instâncias. A personagem discursiva de Volochinov remete ao paradoxo de Münchausen descrito por Michel Pêcheux, no qual o herói esforça-se em se "puxar" pelos cabelos para "progredir" no mundo das ideologias. ${ }^{47}$ É o que Volochinov não torna transparente, o mecanismo do desenvolvimento ideológico. Ele não expõe como o heterogêneo pode aparecer e atuar sobre a consciência no espaço ideológico homogêneo que implica uma "psicologia social" homogênea. É esta a aliança ambivalente com o marxismo oficial que impediu Volochinov de resgatar os mecanismos de toda ideologia, isto é, de determinar, ao lado do aparelho repressivo de Estado, os aparelhos ideológicos de Estado, como fez Althusser em $1970 .{ }^{48}$ Colocando unidade entre a psicologia social e a ideologia, a saber, entre o sujeito e seu meio ideológico, Volochinov torna, finalmente, positivas as evidências de interpelação ideológica do sujeito falante. Parece que uma teoria das ideologias assim como uma teoria da análise do discurso não pode fundar-se senão sob a colocação em dúvida da organicidade, da continuidade e da identidade do sujeito ideológico.

\section{Tradução: Ana Zandwais (PPG-LET - UFRGS)}

\footnotetext{
${ }^{46}$ Oswald Ducrot . Le dire et le dit. Paris, Minuit, 1984.

${ }^{47}$ Ver comentários de D. Maldidier sobre o "efeito Munchause" em Pêcheux em "A Inquietude do discurso. Paris, Ed. des Cendres, 1990.

${ }^{48}$ Louis Althusser em "Os aparelhos ideológicos de Estado" em Positions, Paris, Ed. Sociales, 1976.
} 


\section{REFERÊNCIAS BIBLIOGRÁFICAS}

ALTHUSSER, Louis. Ideologie et appareils idéologiques d'État. Positions, Paris, Ed. Sociales, 1976.

BAKHTIN, Mikhail. Marxisme et philosophie du langage. Prblèmes fondamentaux d'une méthode sociologique appliquée à la science du langage. Paris, Ed. Minuit, 1977.

DUCROT, O. Le dire et le dit. Paris, Ed. Minuit, 1984.

EMERSON, Caryl. The outer word \& inner speech. In Mikhai Bakhtin (GARDINER, Michael) org., London, Ed. Sage, 2002.

GOETHE, Jochan W. La métamorphose des plantes. Paris, Triades, 1975.

HUMBOLDT, W. Schriften zur sprache. Stuttgart, Reklam, 1995.

LÊNINE, Vladimir. Oeuvres choisis. T.1, 1954.

LEONTIEV, A. Dejatelnost. Soznanije. Lithnost. Moscou, Acdémia, 2004.

MALDIDIER, D. L'inquiétud du discours. Paris, Ed. Cendres, 1990.

MALMBERG, Bertil. Histoire de la linguistique de Sumer a Saussure. Paris, Ed. Puf, 1991.

ROSENTHAL, M. LOUDINE, P. Le Petit dictionnaire philosophique. Moscou, 1955.

PAPAIOANNOU, Kostas. Hegel. Paris, Seghers, 1962.

PLEKHANOV, Georges. Euvres philosophiques. Moscou, Ed. Du Progrès, 1981.

SIMMEL, Georg. La forme de l'histoire et autres essais. Paris, Ed. Gallimard, 2004.

Kant et Goethe. Contributions à l'histoire de la pensée moderne. Paris, Ed.

Gallimard, 2005.

. Le problème de la sociologie et autres textes. Paris, Ed. Du Sandre, 2006.

Pour comprendre Nietzsche. Paris, Ed. Gallimard, 2006.

SPENGLER, O. Le déclin de l'Occident. Moscou, Ed. Mysl', 1999

TIHANOV, Galin. Vološinov, ideology and language. In: Mikhail Bakhtin. GARDINER, M. (org.), London, Ed. Sage, 2002.

VINEY, Wayne. A history of Psychology: ideas and context. Boston, London, Ed. Allyn \& Bacon, 1993.

VOLOCHINOV, Valentine. Čto takoje jazik? (Qu'est ce que le langage?) literaturnaja učeba. Moscou, 1930.

WUNDT, W. Völkerpsychologie. Die Sprache, 1900. 